\title{
Comparison of Chemical Composition and Antibacterial Activity of Nigella sativa Seed Essential Oils Obtained by Different Extraction Methods
}

\author{
L. KOKOSKA, ${ }^{1,5 *}$ J. HAVLIK, ${ }^{2}$ I. VALTEROVA, ${ }^{3}$ H. SOVOVA, ${ }^{4}$ M. SAJFRTOVA, ${ }^{4}$ AND I. JANKOVSKA ${ }^{5}$ \\ ${ }^{1}$ Department of Crop Sciences and Agroforestry, Institute of Tropics and Subtropics, Czech University of Life Sciences Prague, Kamycka 129, \\ 16521 Prague 6-Suchdol, Czech Republic; ${ }^{2}$ Department of Microbiology, Nutrition and Dietetics, Faculty of Agrobiology, \\ Food and Natural Resources, Czech University of Life Sciences Prague, Kamycka 129, 16521 Prague 6-Suchdol, Czech Republic; \\ ${ }^{3}$ Department of Natural Products, Institute of Organic Chemistry and Biochemistry, Academy of Sciences of the Czech Republic, Flemingovo n. 2, \\ 16610 Prague 6, Czech Republic; ${ }^{4}$ Department of Diffusion and Separation Processes, Institute of Chemical Process Fundamentals, Academy of \\ Sciences of the Czech Republic, Rozvojova 135, 16502 Prague 6-Suchdol, Czech Republic; and ${ }^{5}$ Department of Zoology and Fisheries, \\ Faculty of Agrobiology, Food and Natural Resources, Czech University of Life Sciences Prague, Kamycka 129, \\ 16521 Prague 6-Suchdol, Czech Republic
}

MS 08-092: Received 18 February 2008/Accepted 2 June 2008

\begin{abstract}
Nigella sativa L. seed essential oils obtained by hydrodistillation (HD), dry steam distillation (SD), steam distillation of crude oils obtained by solvent extraction (SE-SD), and supercritical fluid extraction (SFE-SD) were tested for their antibacterial activities, using the broth microdilution method and subsequently analyzed by gas chromatography and gas chromatographymass spectrometry. The results showed that the essential oils tested differed markedly in their chemical compositions and antimicrobial activities. The oils obtained by HD and SD were dominated by $p$-cymene, whereas the major constituent identified in both volatile fractions obtained by SD of extracted oils was thymoquinone (ranging between 0.36 and $0.38 \mathrm{~g} / \mathrm{ml}$, whereas in oils obtained by HD and SD, it constituted only 0.03 and $0.05 \mathrm{~g} / \mathrm{ml}$, respectively). Both oils distilled directly from seeds showed lower antimicrobial activity (MICs $\geq 256$ and $32 \mu \mathrm{g} / \mathrm{ml}$ for HD and SD, respectively) than those obtained by SE-SD and SFE-SD (MICs $\geq 4 \mu \mathrm{g} / \mathrm{ml}$ ). All oil samples were significantly more active against gram-positive than against gramnegative bacteria. Thymoquinone exhibited potent growth-inhibiting activity against gram-positive bacteria, with MICs ranging from 8 to $64 \mu \mathrm{g} / \mathrm{ml}$.
\end{abstract}

Nigella sativa L., commonly known as black cumin, is an annual plant belonging to the Ranunculaceae family, whose seeds have been traditionally used in the Indian subcontinent, Arabian countries, and Europe for culinary and medicinal purposes (20). During the past few decades, many phytochemical and pharmacological studies have been conducted on $N$. sativa seeds because of its marked biological activities, e.g., antioxidant, anti-inflammatory, antiulcer, anticarcinogenic, immunological, and antiparasitic effects (4). Among them, the antibacterial (or antimicrobial) actions of fixed oil, volatile oil, and various kinds of extracts have thoroughly been studied $(2,18,31,39)$. It was found that the antibacterial activity of the seed was predominantly related to the volatile oil $(19,30)$. Subsequently, the antibacterial properties of the volatile oil of $N$. sativa have been further examined with different types of in vitro $(3,10,15,23,32)$ or in vivo tests $(7,14)$.

The seeds have been reported to contain mainly fixed oils, proteins, alkaloids, saponins, and essential oil that was previously characterized by a higher percentage of monoterpenes, the main constituents being thymoquinone and $p$-cymene (4). However, the significant variations in chemical composition of $N$. sativa seed essential oil have pre-

\footnotetext{
* Author for correspondence. Tel: +420-224382180; Fax: +420-
}

234381829; E-mail: kokoska@its.czu.cz. viously been ascribed to the influence of origin of the plant (29), extraction (36), and agronomic techniques used, e.g., sowing date, irrigation regime, or fertilizer type $(8,12,26)$.

Although some indications that the extraction method used may also affect the biological activity of $N$. sativa essential oil have previously appeared in literature (6), this is the first report demonstrating significant effect of extraction method used on its antibacterial activity.

\section{MATERIALS AND METHODS}

Plant material. The seeds of $N$. sativa were purchased from a local market in Istanbul (Turkey) during July 2003. The voucher specimen (Kok 005) collected from plants growing in experimental fields of the Czech University of Life Sciences Prague was authenticated by Dr. Kokoska, and deposited in the Institute of Tropics and Subtropics Herbarium, Czech University of Life Sciences Prague.

Isolation of essential oils. The seeds were finely ground with a laboratory mill, and particular samples (70 g) were subsequently submitted to the extraction, using four different methods: hydrodistillation (HD), dry steam distillation (SD), steam distillation of crude oils obtained by solvent extraction (SE-SD), and supercritical fluid extraction (SFE-SD). Three replicates were distilled simultaneously for each type of oil extraction. All oil samples were weighed and stored in dark at $4^{\circ} \mathrm{C}$ until their use. The yields ob- 
tained were averaged and calculated based on dry weight of the plant material.

To obtain the essential oil by HD, the material was placed into a water-containing flask connected directly to a condenser (Clevenger-type apparatus), while in the case of SD, the material was placed in a glass column interposed between flask and condenser. Both oils isolated after $2 \mathrm{~h}$ by HD and SD were found to be a pale-yellow liquids, obtained in yields of 0.29 and $0.39 \%$ (wt/wt), respectively.

The SE of the material was carried out with a Soxhlet apparatus, using $n$-hexane as a solvent. After a 120 -h extraction, the solvent was removed in a rotary evaporator; the extract was $45 \%$ (wt/wt) of the starting material. The residue was subjected to steam distillation with $200 \mathrm{ml}$ of water for $1 \mathrm{~h}$, and then volatile components were isolated by extraction with $n$-hexane. The removal of the solvent gave $0.34 \%$ (wt/wt) of the clear, brownish yellow liquid volatile oil.

The supercritical fluid extraction (SFE) was performed in an apparatus as previously described by Sovova et al. (33). A 150$\mathrm{ml}$ stainless steel extractor was loaded with $67 \mathrm{~g}$ of milled seeds. The system was operated at a constant pressure of $25 \mathrm{MPa}$ and temperature of $40^{\circ} \mathrm{C}$. The specific solvent flow related to the seed feed was less than $0.08 \mathrm{~g} / \mathrm{g} / \mathrm{min}$. The obtained saturated solution of seed oil in supercritical carbon dioxide was expanded to atmospheric pressure, and the extract was collected in a cooled glass trap immersed in a dry ice-ethanol bath at $-82^{\circ} \mathrm{C}$. Total extraction yield after $37 \mathrm{~g} \mathrm{CO}_{2}$ per $1 \mathrm{~g}$ of seed passed the extractor was $36.4 \%$ (wt/wt). Since preliminary gas chromatography-mass spectrometry analysis showed a high content of fatty acids, the supercritical extract was subsequently submitted to steam distillation performed under the same conditions as used for the SE residue, giving $0.27 \%$ (wt/wt) of clear, light-brownish yellow volatile fraction, crystalline at room temperature.

Gas chromatography. Analyses were carried out with a Hewlett-Packard 5890 Series II gas chromatograph equipped with a flame ionization detector (Hewlett-Packard, Avondale, Pa). The separations were performed by using a fused silica DB-5 column (30 $\mathrm{m}$ by $0.25 \mathrm{~mm}$, film thickness of $0.25 \mu \mathrm{m}$; J\&W Scientific, Folsom, Calif.). The operating conditions were as follows: injector and detector temperatures, 220 and $250^{\circ} \mathrm{C}$, respectively; carrier gas helium at $1 \mathrm{ml} / \mathrm{min}$; oven temperature program $50^{\circ} \mathrm{C}$ for 5 min, increased to $250^{\circ} \mathrm{C}$ at $4^{\circ} \mathrm{C} / \mathrm{min}$ and held isothermal for 10 min. The samples were diluted to $0.1 \%$ in hexane injected in splitless mode, injection volume being $1 \mu$ l.

Gas chromatography-mass spectrometry. The analysis was performed with a Finnigan Focus GC (Thermo Electron Corporation, Madison, Wis.) coupled to a Fisons MD 800 detector (Fisons Instruments, Vienna, Austria). The apparatus was equipped with a DB-5 fused silica column (30 m by $0.25 \mathrm{~mm}$, film thickness of $0.25 \mu \mathrm{m}$; J\&W Scientific). The operating conditions were as follows: injector and transfer line temperatures 220 and $200^{\circ} \mathrm{C}$, respectively; carrier gas helium at $1 \mathrm{ml} / \mathrm{min}$; ionization energy of $70 \mathrm{eV}$; scan time of $1 \mathrm{~s}$; and a mass range of 30 to 600 amu. Gas chromatographic conditions were as previously stated.

The identification of the chemical constituents was based on comparison of their Kováts retention indices and mass spectra with those listed in Wiley Mass spectral reference library (25), converted for use with the National Institute of Standards and Technology MS Search software (35), and in the National Institute of Standards and Technology library (34), as well as in the literature $(1,22)$. Three minor components were not identified; their mass spectral fragmentation patterns are shown in Table 1.
Bacterial cultures and media. The effectiveness of the essential oils was evaluated against nine bacterial species, selected as representatives of both classes of gram-positive and gram-negative bacteria. The following American Type Culture Collection (ATCC) strains were used: Bacillus cereus ATCC 11778, Bacillus subtilis ATCC 6633, Bacteroides fragilis ATCC 25285, Enterococcus faecalis ATCC 29212, Escherichia coli ATCC 25922, Pseudomonas aeruginosa ATCC 27853, Staphylococcus aureus subsp. aureus ATCC 25923, Staphylococcus epidermidis ATCC 12228, and Streptococcus pyogenes ATCC 19615.

B. fragilis, as a representative of anaerobic bacteria, was grown in a Wilkins-Chalgren anaerobe broth under anaerobic conditions, using the Anaerobic Jar HP11 (Oxoid, Ltd., Basingstoke, $\mathrm{UK}), S$. pyogenes was grown in brain heart infusion broth, and other bacteria were tested in Mueller-Hinton broth. All microbial strains and cultivation media were purchased from Oxoid. The susceptibility of all bacterial strains to ciprofloxacin (Sigma-Aldrich, Prague, Czech Republic) was checked as a positive control (Table 2).

Antimicrobial assay. In vitro antimicrobial activity was determined by the broth microdilution method using 96-well microtiter plates (21). Initially, each sample of essential oil was mixed with an appropriate volume of Tween 80 (Sigma-Aldrich) to give a final concentration of $0.5 \%$ in broth medium adjusted to $\mathrm{pH} 7.6$, using Tris-buffered saline (Sigma-Aldrich). In the case of thymoquinone (Sigma-Aldrich), the sample was also first mixed with Tween 80 and then with an appropriate volume of ethanol to give final respective concentrations of 0.5 and $1 \%$ in broth medium prepared with Tris-buffered saline. Two-fold dilutions (1) of each sample tested were subsequently carried out, starting from concentrations of 1,024 and $512 \mu \mathrm{g} / \mathrm{ml}$ for essential oils and thymoquinone, respectively. Each well was inoculated with $5 \mu \mathrm{l}$ of bacterial suspension at a density of $10^{7} \mathrm{CFU} / \mathrm{ml}$. The microtiter plates were incubated at $37^{\circ} \mathrm{C}$ for $24 \mathrm{~h}$ and then observed for the MIC. The growth of microorganisms was observed as turbidity determined by the UV-VIS spectrophotometer Helios $\varepsilon$ (Spectronic Unicam, Cambridge, UK) at $600 \mathrm{~nm}$. MICs were calculated based on the density of the growth control and were the lowest oil concentrations that resulted in an $80 \%$ reduction in growth compared with that of the oil-free growth control. Tween 80 $(0.5 \%)$, as well as a mixture of Tween $80(0.5 \%)$ and ethanol $(1 \%)$ assayed as the negative controls, did not inhibit any of tested bacterial strains. The replicates obtained for each type of oil extraction were mixed together prior their testing. All samples were tested in triplicate.

Statistical analysis. The quantitative data of major components of oil ( $p$-cymene, $\alpha$-thujene, and thymoquinone) were statistically examined by one-way analysis of variance (ANOVA), and significant differences among groups were subsequently analyzed by Duncan's multiple range test $(P<0.05)$.

Correlation coefficient calculated from averaged MICs of all bacterial strains tested and averages of quantitative data individual compounds were used to express association between antibacterial activities of tested oils and their contents of components indicated as antibacterial active (thymoquinone and carvone). To calculate averages of MICs, values quantified greater than maximum concentration tested $(>1,024$ and $>512)$ were replaced by 1,024 and 512 for oils and thymoquinone, respectively.

All statistical analyses were performed with the STATISTICA 6 software (5).

\section{RESULTS AND DISCUSSION}

The results of gas chromatography-mass spectrometry analysis showed that essential oils obtained by different ex- 
TABLE 1. Comparison of chemical constitution of the N. sativa essential oils obtained by different extraction methods

\begin{tabular}{|c|c|c|c|c|c|c|}
\hline \multirow[b]{2}{*}{ No. } & \multirow[b]{2}{*}{ Compound } & \multirow[b]{2}{*}{$\mathrm{RI}^{a}$} & \multicolumn{4}{|c|}{ Extraction method/peak area $(\%)^{b}$} \\
\hline & & & HD & SD & SE-SD & SFE-SD \\
\hline 1 & $\alpha$-Thujene ${ }^{c}$ & 931 & 15.1 & 17.5 & 4.1 & 0.3 \\
\hline 2 & $\alpha$-Pinene & 939 & 3.3 & 3.8 & 0.9 & $\mathrm{~T}^{d}$ \\
\hline 3 & Sabinene & 976 & 2 & 1.9 & 0.9 & $\mathrm{~T}$ \\
\hline 4 & $\beta$-Pinene & 980 & 4 & 4.2 & 1.8 & $\mathrm{~T}$ \\
\hline 5 & $n$-Decane & 1,000 & - & - & 0.3 & - \\
\hline 6 & $\alpha$-Phellandrene & 1,006 & $\mathrm{~T}$ & $\mathrm{~T}$ & - & - \\
\hline 7 & $\alpha$-Terpinene & 1,018 & 0.7 & 0.6 & 0.3 & $\mathrm{~T}$ \\
\hline 8 & $p$-Cymene ${ }^{c}$ & 1,026 & $56.2^{e}$ & 52.0 & 42.4 & 8.6 \\
\hline 9 & Limonene & 1,031 & 2.9 & 2.9 & 2.1 & - \\
\hline 10 & $\gamma$-Terpinene & 1,062 & 1.2 & 0.7 & 1 & $\mathrm{~T}$ \\
\hline 11 & Isoterpinolene & 1,081 & - & - & - & $\mathrm{T}$ \\
\hline 12 & p-Cymenene & 1,089 & - & $\mathrm{T}$ & $\mathrm{T}$ & $\mathrm{T}$ \\
\hline 13 & Linalool & 1,098 & $\mathrm{~T}$ & $\mathrm{~T}$ & $\mathrm{~T}$ & 0.1 \\
\hline 14 & Unknown $1^{f}$ & 1,099 & 1 & 1 & 1.1 & 0.4 \\
\hline 15 & $n$-Undecane & 1,100 & - & - & 0.5 & - \\
\hline 16 & Unknown $2^{f}$ & 1,116 & 6.3 & 5.3 & 6.1 & 3.5 \\
\hline 17 & Limonene oxide & 1,134 & - & - & $\mathrm{T}$ & - \\
\hline 18 & Camphor & 1,140 & - & $\mathrm{T}$ & - & - \\
\hline 19 & Unknown $3^{f}$ & 1,159 & 0.4 & 0.4 & 0.6 & - \\
\hline 20 & Terpinen-4-ol & 1,177 & 0.9 & 0.6 & 0.8 & 1.4 \\
\hline 21 & $p$-Cymen-8-ol & 1,183 & - & - & 0.2 & - \\
\hline 22 & $\beta$-Cyclocitral & 1,196 & - & - & 0.4 & - \\
\hline 23 & Carvone & 1,242 & 1.1 & 1 & 1.3 & 0.8 \\
\hline 24 & Thymoquinone $^{c}$ & 1,249 & 0.5 & 4.3 & 30.7 & 76.7 \\
\hline 25 & Linalool acetate & 1,257 & $\mathrm{~T}$ & $\mathrm{~T}$ & $\mathrm{~T}$ & $\mathrm{~T}$ \\
\hline 26 & Bornyl acetate & 1,285 & 0.2 & - & 0.8 & 0.7 \\
\hline 27 & Thymol & 1,288 & - & $\mathrm{T}$ & - & $\mathrm{T}$ \\
\hline 28 & Carvacrol & 1,296 & 0.8 & 0.6 & 1 & 2.5 \\
\hline 29 & $\alpha$-Longipinene & 1,351 & 0.7 & 0.6 & 0.6 & 0.9 \\
\hline 30 & Longifolene & 1,402 & 2.6 & 2.2 & 1.8 & 2.6 \\
\hline 31 & $\beta$-Caryophyllene & 1,408 & 0.1 & 0.4 & - & 0.3 \\
\hline 32 & $\beta$-Bisabolene & 1,505 & $\mathrm{~T}$ & $\mathrm{~T}$ & - & 0.3 \\
\hline 33 & $\gamma$-Cadinene & 1,513 & $\mathrm{~T}$ & - & 0.3 & 0.9 \\
\hline 34 & Thymohydroquinone & 1,553 & $\mathrm{~T}$ & - & $\mathrm{T}$ & - \\
\hline 35 & $(2 E, 6 E)$-Farnesol & 1,723 & - & - & - & $\mathrm{T}$ \\
\hline \multicolumn{2}{|c|}{ Total peak area $(\%)$} & & 92.3 & 93.3 & 92.2 & 96.1 \\
\hline \multicolumn{2}{|c|}{ Monoterpene hydrocarbons } & & 85.4 & 83.6 & 53.5 & 8.9 \\
\hline \multicolumn{2}{|c|}{ Oxygenated monoterpenes } & & 3.5 & 6.5 & 35.2 & 82.2 \\
\hline \multicolumn{2}{|c|}{ Sesquiterpene hydrocarbons } & & 3.4 & 3.2 & 2.7 & 5 \\
\hline \multicolumn{2}{|c|}{ Oxygenated sesquiterpenes } & & - & - & - & $\mathrm{T}$ \\
\hline \multicolumn{2}{|c|}{ Others } & & - & - & 0.8 & - \\
\hline
\end{tabular}

${ }^{a}$ RI, retention indices relative to $\mathrm{C}_{8}-\mathrm{C}_{22} n$-alkanes on DB-5 capillary column.

${ }^{b}$ Mean of three replicates. HD, hydrodistillation; SD, dry steam distillation; SE-SD, steam distillation of crude oil obtained by solvent extraction; SFE-SD, steam distillation of crude oil obtained by SFE.

${ }^{c}$ The main constituents $(>10 \%)$ statistically examined compounds, using the one-way ANOVA procedure.

${ }^{d} \mathrm{~T}$, trace $(<0.05 \%)$.

${ }^{e}$ Not significantly different at the level $P<0.05$ according to the Duncan's test.

${ }^{f}$ Spectral data of unidentified and tentatively identified constituents. MS, $m / z$ (relative intensity): unknown 1: 168 (M ${ }^{+}$, not present), 153 (21), 93 (100), 85 (88), 125 (74), 72 (68), 43 (54), 55 (53), 41 (54), 81 (45), 100 (40); unknown 2: 168 (M+, not present), 153 (46), 72 (100), 85 (90), 93 (83), 125 (68), 55 (65), 81 (60), 43 (58), 41 (57), 69 (36); unknown 3: 168? (M+, not present), 152 (7), 43 (100), 67 (57), 109 (45), 41 (33), 81 (33), 79 (22), 39 (21), 55 (19), 91 (17).

traction methods from seeds of $N$. sativa seeds differ significantly $(P<0.05)$ in percentage compositions of the main constituents detected. The compounds characterized in the oils are given in Table 1.

More than $92.2 \%$ of the essential oil analyzed was identified in each sample, and 35 different compounds were determined in total. The main constituents in oils obtained by HD, SD, and SE-SD were monoterpene hydrocarbons, which were followed by oxygenated monoterpenes and sesquiterpene hydrocarbons. However, there were marked qualitative differences between the oil distilled using SESD and of those obtained by both direct distillations, rep- 
TABLE 2. Antibacterial activity of thymoquinone and N. sativa seed essential oils obtained by different extraction methods

\begin{tabular}{|c|c|c|c|c|c|c|}
\hline \multirow[b]{3}{*}{ Bacteria } & \multicolumn{6}{|c|}{ MICs $(\mu \mathrm{g} / \mathrm{ml})$} \\
\hline & \multicolumn{4}{|c|}{ Essential oils ${ }^{a}$} & \multirow[b]{2}{*}{$\mathrm{TQ}^{b}$} & \multirow[b]{2}{*}{$\mathrm{CIP}^{c}$} \\
\hline & $\mathrm{HD}$ & SD & SE-SD & SFE-SD & & \\
\hline \multicolumn{7}{|l|}{ Gram-positive } \\
\hline Bacillus cereus & 512 & 32 & 8 & 4 & 8 & 1 \\
\hline B. subtilis & 512 & 64 & 8 & 8 & 64 & 2 \\
\hline Enterococcus faecalis & $>1,024$ & 128 & 16 & 16 & 32 & 1 \\
\hline Staphylococcus aureus & 512 & 32 & 4 & 4 & 8 & 1 \\
\hline S. epidermidis & 256 & 32 & 4 & 4 & 8 & 1 \\
\hline Streptococcus pyogenes & 512 & 256 & 64 & 32 & 8 & 0.5 \\
\hline \multicolumn{7}{|l|}{ Gram-negative } \\
\hline Bacteroides fragilis & $>1,024$ & $>1,024$ & 64 & 32 & 64 & 2 \\
\hline Escherichia coli & $>1,024$ & $>1,024$ & 512 & 256 & 512 & 0.03 \\
\hline Pseudomonas aeruginosa & $>1,024$ & $>1,024$ & $>1,024$ & $>1,024$ & $>512$ & 0.5 \\
\hline
\end{tabular}

${ }^{a}$ Extraction method: HD, hydrodistillation; SD, dry steam distillation; SE-SD, steam distillation of crude oil obtained by solvent extraction; SFE-SD, steam distillation of crude oil obtained by supercritical fluid extraction.

$b$ TQ, thymoquinone.

${ }^{c}$ CIP, ciprofloxacin (positive reference standard).

resented by $85.4,83.6$, and $53.5 \%$ of monoterpene hydrocarbons and by $3.5,6.5$, and $35.2 \%$ of oxygenated monoterpenes for $\mathrm{HD}, \mathrm{SD}$, and SE-SD, respectively. In contrast, the essential oil isolated by SFE-SD was characterized by a high degree of oxygenated monoterpenes (82.2\%), but monoterpene hydrocarbons were present in a relatively small amount (8.9\%).

Although the hydro- and steam-distilled oils were closely similar in terms of chemical composition, both containing mainly $p$-cymene $(56.2 \%$ for $\mathrm{HD}$ and $52.0 \%$ for $\mathrm{SD}$ ), according to the statistical analysis, they differed slightly in percentage of $\alpha$-thujene $(15.1 \%$ for HD and $17.5 \%$ for $\mathrm{SD}$ ) and thymoquinone, which was the third main identified compound of oil obtained by SD (4.3\%), while in the hydrodistilled oil, it was present only as a minor component $(0.5 \%)$. In the case of SE-SD oil, $p$-cymene $(42.4 \%)$ and thymoquinone $(30.7 \%)$ were found to be the main components, while $\alpha$-thujene was present as a less abundant compound (4.1\%). In contrast to all other samples analyzed, the oil isolated by SFE-SD was chiefly composed of thymoquinone (76.7\%), with only low amounts of $p$-cymene $(8.6 \%)$ and $\alpha$-thujene $(0.3 \%)$. The subsequent quantitative analysis of all essential oil samples confirmed that thymoquinone is the major constituent of both volatile fractions obtained by SD of extracted oils, with content ranging from 0.36 to $0.38 \mathrm{~g} / \mathrm{ml}$, whereas in oils obtained by HD and SD, it constituted only 0.03 and $0.05 \mathrm{~g} / \mathrm{ml}$, respectively.

The results of the in vitro antibacterial testing of $N$. sativa seed essential oils obtained by different extraction methods are presented in Table 2. It was observed that all samples tested possessed antibacterial activity against at least one of the bacterial strains tested; however, their effectiveness differs greatly depending to the extraction method used.

As far as the potencies of individual samples are concerned, the essential oil obtained by SFE-SD showed the strongest antibacterial activity against all bacterial strains tested, closely followed by the oil obtained by SE-SD. Although both volatile fractions strongly inhibited most of the bacteria tested (MICs $\geq 4 \mu \mathrm{g} / \mathrm{ml}$ ), the oil obtained by SFESD was slightly more active, demonstrating lower MICs for more strains than oil obtained by SE-SD. The steam-distilled oil exhibited lower inhibitory activity (MICs $\geq 32$ $\mu \mathrm{g} / \mathrm{ml}$ ) in comparison with both volatile fractions isolated from extracted oils; however, it possessed a stronger effect than hydrodistilled oil possessed, which was the weakest antibacterial active sample (MICs $\geq 256 \mu \mathrm{g} / \mathrm{ml}$ ) among all oils assayed in this study. In the presence of any essential oil tested, the strongest activity was observed against $S$. epidermidis, with MICs ranging from 4 to $256 \mu \mathrm{g} / \mathrm{ml}$, which was followed by $B$. cereus and $S$. aureus, with MICs ranging from 4 to $512 \mu \mathrm{g} / \mathrm{ml}$. The weakest activity was observed against $P$. aeruginosa (MICs $>1,024 \mu \mathrm{g} / \mathrm{ml}$ ). All samples tested in this study were significantly more active against gram-positive than against gram-negative bacteria, which is consistent with observations frequently reported in literature $(2,3,10,19,31,32,38)$.

Thymoquinone possessed significant antibacterial activity, with MICs very close to effects of both essential oils obtained by SE-SD and SFE-SD, inhibiting mainly the growth of gram-positive bacteria, whereas B. cereus, S. aureus, $S$. epidermidis, and $S$. pyogenes were the species most sensitive (MICs were $8 \mu \mathrm{g} / \mathrm{ml}$ ).

Previously, different extraction methods, e.g., Clevenger hydrodistillation and steam distillation of seeds or their oils, have been used to obtain antibacterial active essential oil from $N$. sativa $(2,3,10,15,19,23,30-32,39)$. However, according to our results, the techniques based on steam distillation of extracted seed oils (SE-SD and SESFE) provide markedly more effective essential oil than do HD and SD of seeds. Although the oil obtained by SD showed a certain degree of inhibitory activity against some gram-positive strains, we consider both direct seed distil- 
lation methods to be less convenient for production of antibacterial active essential oils. Additionally, according to our results with steam-distilled essential oil from SFE extract, the direct extraction with supercritical $\mathrm{CO}_{2}$ seems to be the most promising method for isolation of extremely thymoquinone-rich and highly effective antibacterial fractions of $N$. sativa seeds.

Thymoquinone has been the subject of many pharmacological studies because of its marked biological activities, e.g., antioxidant, anti-inflammatory, and anticarcinogenic effects (4). Its potent growth-inhibiting activity against methicillin-resistant $S$. aureus has been described in a previous study carried on different quinonoid compounds (24). In addition, a closely related thymohydroquinone, isolated from $N$. sativa essential oil, was found to be a highly active substance, inhibiting gram-positive bacteria $(9,38)$. Additionally, some other compounds identified in the majority of samples tested during our study such as phenolic or ketone terpenoids (e.g., carvacrol and carvone) have been reported to be effective against various microorganisms (17). Since we observed a strong concentration-dependent inverse correlation between MICs of tested oils and their contents of thymoquinone $(r=-0.82)$, we suppose that this substance significantly affects antimicrobial action of $N$. $s a$ tiva essential oil. However, we suggest that some other antibacterial active compounds detected in some samples at relatively higher concentrations such as carvacrol or carvone, sometimes discussed as a compound responsible for the antibacterial properties of $N$. sativa essential oil (30), may also contribute to its general inhibitory activity. Moreover, the detected traces of thymohydroquinone, which has been frequently mentioned in relation to antibacterial properties of $N$. sativa $(11,16,28,31)$, are probably not sufficient to significantly influence the general antibacterial action of the samples tested.

$N$. sativa has been used for thousands of years as a spice, condiment, carminative, and food preservative. In conforming with this tradition, several attempts to use its seeds or seed oil during processing and preservation of various food products (e.g., cheese) have been performed in order to improve their stability and microbial safety (13, 37). Moreover, N. sativa seed crude oil possessed significant growth inhibitory activity against various typical foodborne bacterial pathogens such as Listeria monocytogenes, indicating potential of its application as an antibacterial agent in foods (27). However, in previous studies, it was demonstrated that the general antibacterial activity of $N$. sativa seeds was more related to its essential oil $(19,30)$, suggesting this highly effective and chemically well-characterized volatile fraction as a prospective product for food preservation. Nevertheless, according to our results, the use of different methods for extraction of $N$. sativa seeds has a significant influence on the composition and antimicrobial effectiveness of the obtained volatile oil. In our opinion, this finding is of crucial importance for future research in the possible application of $N$. sativa as a food preservative as well as on technology and processing of antimicrobially effective products based on $N$. sativa essential oil.

In summary, we can report that the use of different methods for extraction of $N$. sativa seeds has a significant influence on the composition and antimicrobial activity of the obtained essential oil. According to our results, the steam distillations of crude oils obtained by SE and SFE seem to be convenient methods for obtaining of $N$. sativa essential oil, highly effective against a broad spectrum of gram-positive bacteria. However, conditions of SFE should be optimized for better selectivity of volatile components in order to avoid two final steps of the SFE-SD process, when the residue is subjected to steam distillation, and a volatile fraction is isolated by extracting with an organic solvent. In addition, since thymoquinone exhibits a strong correlation between its percentage content and antibacterial effectiveness of all samples tested, we believe it is the active principle responsible for the antibacterial profile of the $N$. sativa essential oil.

\section{ACKNOWLEDGMENTS}

This research was supported by Czech Science Foundation (project 525/08/1179). The authors are grateful to Brian Kavalir for final linguistic revision of the English text.

\section{REFERENCES}

1. Adams, R. P. 1995. Identification of essential oil components by gas chromatography/mass spectrometry. Allured, Carol Stream, Ill.

2. Agarwal, R., M. D. Kharya, and R. Shrivastava. 1979. Antimicrobial and anthelmintic activities of the essential oil of Nigella sativa Linn. Indian J. Exp. Biol. 17:1264-1265.

3. Akgul, A. 1989. Antimicrobial activity of black cumin (Nigella sativa L.) essential oil. J. Fac. Pharm. Gazi 6:63-68.

4. Ali, B. H., and G. Blunden. 2003. Pharmacological and toxicological properties of Nigella sativa. Phytother. Res. 17:299-305.

5. Anonymous. 2001. STATISTICA (data analysis software system), ver. 6 (CD-ROM). StatSoft, Tulsa, Okla.

6. Burits, M., and F. Bucar. 2000. Antioxidant activity of Nigella sativa essential oil. Phytother. Res. 14:323-328.

7. Chowdhury, A. K. A., A. M. Islam, A. M. Rashid, and A. J. Ferdous. 1998. Therapeutic potential of the volatile oil of Nigella sativa seeds in monkey model with experimental shigellosis. Phytother. Res. 12: 361-363.

8. D'Antuono, L. F., A. Moretti, and A. F. S. Lovato. 2002. Seed yield, yield components, oil content and essential oil content and composition of Nigella sativa L. and Nigella damascena L. Ind. Crops Prod. 15:59-69.

9. El-Alfy, T. S., H. M. El-Fatatry, and M. A. Toama. 1975. Isolation and structure assignment of an antimicrobial principle from the volatile oil of Nigella sativa L. seeds. Pharmazie 30:109-111.

10. El-Kamali, H. H., A. S. Mohammed, A. A. M. Yahia, I. H. El-Tayeb, and A. A. Ali. 1998. Antibacterial properties of essential oils from Nigella sativa seeds, Cymbopogon citratus leaves and Pulicaria undulata aerial parts. Fitoterapia 69:77-78.

11. El-Komey, A. G. 1996. Effect of black seeds (Nigella sativa L.) during pregnancy and lactation on mammary gland development in rat. Alex. J. Agric. Res. 41:63-74.

12. El-Sayed, K. A., S. A. Ross, M. A. El-Sohly, M. M. Khalafalla, O. B. Abdel-Halim, and F. Ikegami. 2000. Effect of different fertilizers on the amino acid, fatty acid, and essential oil composition of Nigella sativa seeds. Saudi Pharm. J. 8:175-182.

13. El-Sayed, M. M., H. A. El-Banna, and F. A. Fathy. 1996. The use of Nigella sativa oil as a natural preservative agent in processed cheese spread. Egypt. J. Food Sci. 22:381-396.

14. Fazly Bazzaz, B. S., H. Hosseinzadeh, and M. Motevaly Haghi. 2002. Antibacterial activity of total extracts and essential oil of $\mathrm{Ni}$ gella sativa seed on mice. J. Pharm. Pharmacol. 54:S1.

15. Ferdous, A. J., S. N. Islam, M. Ahsam, C. M. Hasan, and Z. U. Ahmed. 1992. In vitro antibacterial activity of the volatile oil of 
Nigella sativa seeds against multiple drug-resistant isolates of Shigella spp. and isolates of Vibrio cholerae and Escherichia coli. Phytother. Res. 6:137-140.

16. Ghosheh, O. A., A. A. Houdi, and P. A. Crooks. 1999. High performance liquid chromatographic analysis of the pharmacologically active quinones and related compounds in the oil of the black seed (Nigella sativa L.). J. Pharm. Biomed. 19:757-762.

17. Griffin, S. G., S. G. Wyllie, J. L. Markham, and D. N. Leach. 1999. The role of structure and molecular properties of terpenoids in determining their antimicrobial activity. Flavour Fragr. J. 14:322-332.

18. Hanafy, M. S., and M. E. Hatem. 1991. Studies on the antimicrobial activity of Nigella sativa seed (black cumin). J. Ethnopharmacol. 34:275-278.

19. Hasan, C. M., M. Ahsan, and S. N. Islam. 1989. In vitro antibacterial screening of the oils of the Nigella sativa seeds. Bangladesh J. Bot. 18:171-174.

20. Ipor, I. B., and L. P. A. Oyen. 1999. Nigella sativa L., p. 148-151. In C. C. Guzman and J. S. Siemonsma (ed.), Plant resources of Southeast Asia, no. 13. Backhuys Publishers, Leiden, The Netherlands.

21. Jorgensen, J. H., J. D. Turnidge, and J. A. Washington. 1999. Antibacterial susceptibility tests: dilution and disk diffusion methods, p. 1526-1543. In P. R. Murray (ed.), Manual of clinical microbiology, 7th ed. ASM Press, Washington, D.C.

22. Joulain, D., and W. A. König. 1998. The atlas of spectral data of sesquiterpene hydrocarbons. E. B.-Verlag, Hamburg, Germany.

23. Karawaya, M. S., F. M. Hashim, S. M. A. El-Wahab, K. S. El-Deeb, S. N. Soliman, I. A. Salam, N. Mokhtar, and S. El-Hossiny. 1994. Essential oil and lipids of Nigella sativa seed and their biological activity. Zagazig J. Pharm. Sci. 3:49-57.

24. Liu, M., S. Koya, H. Furuta, and S. Matsuzaki. 1996. Growth-inhibiting activity of antraquinones and benzoquinones against methicillin-resistant Staphylococcus aureus (MRSA). Dokkyo J. Med. Sci. 23:85-93.

25. McLafferty, F. W., and D. B. Stauffer. 1994. Wiley registry of mass spectral data, 6th ed. Mass spectrometry library search system bench-TOP/PBM, ver. 3.10d. Palisade, Newfield, N.Y.

26. Mozaffari, F. S., M. Ghorbanli, A. Babai, and M. F. Sepehr. 2000. The effect of water stress on the seed oil of Nigella sativa L. J. Essent. Oil Res. 12:36-38.
27. Nair, M. K. M., P. Vasudevan, and K. Venkitanarayanan. 2005. Antibacterial effect of black seed oil on Listeria monocytogenes. Food Control 16:395-398.

28. Nergiz, C., and S. Otles. 1993. Chemical composition of Nigella sativa L. seeds. Food Chem. 48:259-261.

29. Nickavar, B., F. Mojab, K. Javidnia, and M. A. R. Amoli. 2003. Chemical composition of the fixed and volatile oils of Nigella sativa L. from Iran. Z. Naturforsch. 58c:629-631.

30. Rathee, P. S., S. H. Mishara, and R. Kaushal. 1982. Antimicrobial activity of essential oil, fixed oil and unsaponified matter of Nigella sativa L. Indian J. Pharm. Sci. 44:8-10.

31. Sarhan, A., T. Al-Faitury, S. Al-Khitaly, and A. Fowad. 1996. Chemical composition and antibacterial activity of Nigella sativa L. seeds oil. J. Sebha Univ. B 3:49-59.

32. Singh, G., P. Marimuthu, C. S. de Heluani, and C. Catalan. 2005. Chemical constituents and antimicrobial and antioxidant potentials of essential oil and acetone extract of Nigella sativa seeds. J. Sci. Food Agric. 85:2297-2306.

33. Sovova, H., R. Komers, J. Kucera, and J. Jez. 1994. Supercritical carbon dioxide extraction of caraway essential oil. Chem. Eng. Sci. 49:2499-2505.

34. Stein, S. E. 2002. NIST/EPA/NIH mass spectral library (NIST 02) (software), ver. 2002. National Institute of Standards and Technology, Gaithersburg, Md.

35. Stein, S. E., Y. Mirokhin, D. D. Tchekhovskoi, and G. Mallard. 2002. The NIST mass spectral search program for the NIST/EPA/NIH mass spectral library (software), ver. 2.0a. National Institute of Standards and Technology, Gaithersburg, Md.

36. Stoyanova, A., E. Georgiev, A. Wajs, and D. Kalemba. 2003. A comparative investigation on the composition of the volatiles from seeds of Nigella sativa L. from Bulgaria. J. Essent. Oil-Bear. Plant. 6:207-209.

37. Tarakci, Z., K. Ekici, O. Sagdic, and E. Kucukoner. 2005. The effect of black cumin on ripening of Tulum cheese. Arch. Lebensmittelhyg. $56: 135-139$

38. Toama, M. A., T. S. El-Alfy, and H. M. El-Fatatry. 1974. Antimicrobial activity of the volatile oil of Nigella sativa Linneaus seeds. Antimicrob. Agents Chemother. 6:225-226.

39. Toppozada, H. H., H. A. Mazloum, and M. El-Dakhakhny. 1965. The antibacterial properties of Nigella sativa seeds. Active principle with some clinical applications. J. Egypt. Med. Assoc. 48:187-202. 